\title{
Direct Measurement of Intermolecular Mechanical Force for Non-specific Interactions between Small Molecules
}

\author{
Shankar Pandey¹, Yuan Xiang², Dirk Friedrich'1, Yongsheng Leng², Hanbin Mao1,* \\ 1. Department of Chemistry and Biochemistry, Kent State University, Kent, OH, 44242, USA \\ 2. Department of Mechanical and Aerospace Engineering, The George Washington University, \\ Washington, DC 20052, USA
}




\section{Material and Methods:}

\section{Molecular simulation methods}

Nonequilibrium steered molecular dynamics (SMD) simulations are performed at $296 \mathrm{~K}$ and $1 \mathrm{~atm}$ pressure in an NPT ensemble by using the LAMMPS computational package. ${ }^{\mathrm{S} 1}$ To simplify the simulation setup, the two cholesterol linkers in the single-molecule platform are assumed to connect to either the oxygen atom in the hydroxyl group or the $\mathrm{C} 25$ atom in each cholesterol molecule (Figure 1), and are arranged in close proximity prior to the mechanical pulling. The two linkers are connected to a driving spring on each side to mimic the dissociation force (IMMF) measurements. Pulling the oxygen atom or the $\mathrm{C} 25$ atom in the cholesterol dimer mimics the pulling from the hydroxyl head or from the alkyl tail (Figure 1), respectively. The pulling speed is set to $0.002 \AA / \mathrm{ps}$.

We use the particle-particle particle-mesh solver to calculate the long-range electrostatic interactions. ${ }^{\mathrm{S} 2}$ Periodic boundary conditions are applied in three dimensions. The cutoff distance for the short-range Lennard-Jones interactions is set to $10 \AA$. The temperature is controlled at 296 $\mathrm{K}$ by the Nosé-Hoover thermostat. ${ }^{\mathrm{S} 3}$ The equations of motion of the particles are propagated through the velocity Verlet algorithm with a time step of $1 \mathrm{fs}$ in a constant- $N P T$ ensemble. We use the consistent valence force field $(\mathrm{CVFF})^{\mathrm{S} 4}$ to describe the interatomic interactions between all atoms. Atomic partial charges for cholesterol molecules are recalibrated by using quantum mechanical density functional theory calculations with the B3LYP/6-31G** functional and basis set and by the CHarges from ELectrostatic Potentials using a Grid (CHELPG)-based method. ${ }^{\mathrm{S} 5}$ The flexible simple-point charge (SPC) model is used for water in our system, ${ }^{\mathrm{S} 6-7}$ which is consistent with the CVFF force field parameters. We also applied the other two popular force fields, the general AMBER force field (GAFF) ${ }^{\mathrm{S} 8}$ and the $\mathrm{CHARMM} 36^{\mathrm{S} 9}$ to check against the CVFF for the purpose of verification and validation of simulation results. Negligible effects are found on the dissociation force from all three force fields. Consequently, only the results from the CVFF are reported in this work.

\section{General Experimental}

Oligonucleotides were purchased from the IDT (Integrated DNA Technologies, IA). For the preparation of DNA constructs, enzymes were purchased from NEB (New England Biolab, England). Streptavidin or anti-digoxigenin coated polystyrene bead were purchased from 
Spherotech (Lake Forest, IL). Azido-TEG-cholesterol and 27-alkyne cholesterol were purchased from Sigma Aldrich and Click Chemistry Tools, respectively. Unless otherwise stated, all chemicals and solvents were purchased from Sigma Aldrich or Fisher Scientific and used without further purification.

\section{Synthesis of cholesterol functionalized DNA}

\section{Synthesis of 5' Cholesterol-TEG-DNA.}

A solution of $8 \mu \mathrm{L}(250 \mu \mathrm{M}) 5^{\prime}$ hexynyl modified DNA was taken in an Eppendorf tube and mixed with $2 \mu \mathrm{L}(10 \mathrm{mM})$ azido-TEG-cholesterol. Then, the reaction mixture was treated with $3 \mu \mathrm{l}$ click solution containing $1 \mu \mathrm{L}$ of $\mathrm{CuBr}$ solution $(0.01 \mathrm{~g}$ of $\mathrm{CuBr}$ in $700 \mu \mathrm{L}$ of $\mathrm{DMSO} / \mathrm{t}-\mathrm{BuOH}$ in 3:1) and $2 \mu \mathrm{L}$ Tris[(1-benzyl-1H-1,2,3-triazol-4-yl)methyl]amine (TBTA) ligand solution. $\mathrm{N}_{2}$ gas was purged to the solution and shaken in dark for $14 \mathrm{hrs}$ at room temperature. Ethanol precipitation was performed to remove unreacted reactants from the reaction mixture, and the precipitant was dissolved in $15 \mu 1$ water. The click product was analyzed and purified with the $15 \%$ denature PAGE gel (Figures S2 and S3) and the structure was confirmed by ESI-HRMS (Figure S4).

\section{Synthesis of 5' Cholesterol-DNA.}

A solution of $8 \mu \mathrm{L}(250 \mu \mathrm{M}) 5^{\prime}$ azide modified DNA was taken in an Eppendorf tube and mixed with $2 \mu \mathrm{L}(10 \mathrm{mM}) 27$-alkyne cholesterol. Then, the reaction mixture was treated with $3 \mu 1$ click solution containing $1 \mu \mathrm{L}$ of $\mathrm{CuBr}$ solution $(0.01 \mathrm{~g}$ of $\mathrm{CuBr}$ in $700 \mu \mathrm{L}$ of $\mathrm{DMSO} / \mathrm{t}-\mathrm{BuOH}$ in 3:1) and $2 \mu \mathrm{L}$ Tris[(1-benzyl-1H-1,2,3-triazol-4-yl)methyl]amine (TBTA) ligand solution. $\mathrm{N}_{2}$ gas was purged to the solution and shaken in dark for $14 \mathrm{hrs}$ at room temperature. Ethanol precipitation was performed to remove unreacted reactants from the reaction mixture, and the precipitant was dissolved in $15 \mu 1$ water. The click product was analyzed and purified with the $15 \%$ denature PAGE gel (Figures S5 and S6).

\section{Synthesis of 3' Cholesterol-propyl-DNA.}

A solution of $8 \mu \mathrm{L}(250 \mu \mathrm{M}) 3^{\prime}$ azido-propyl modified DNA was taken in an Eppendorf tube and mixed with $2 \mu \mathrm{L}(10 \mathrm{mM}) 27$-alkyne cholesterol. Then, the reaction mixture was treated with $3 \mu \mathrm{l}$ click solution containing $1 \mu \mathrm{L}$ of $\mathrm{CuBr}$ solution $(0.01 \mathrm{~g}$ of $\mathrm{CuBr}$ in $700 \mu \mathrm{L}$ of DMSO/t-BuOH in 3:1) and $2 \mu \mathrm{L}$ Tris[(1-benzyl-1H-1,2,3-triazol-4-yl)methyl]amine (TBTA) ligand solution. $\mathrm{N}_{2}$ 
gas was purged to the solution and shaken for $14 \mathrm{hrs}$ in dark at room temperature. Ethanol precipitation was performed to remove unreacted reactants from the reaction mixture, and the precipitant was dissolved in $15 \mu \mathrm{l}$ water. The click product was analyzed and purified with the $12 \%$ denature PAGE gel (Figures S7 and S8).

\section{Synthesis of 3 ' Cholesterol-TEG-DNA.}

A solution of $8 \mu \mathrm{L}(250 \mu \mathrm{M})$ 3' 5-Octadiynyl deoxyuridine modified DNA was taken in an Eppendorf tube and mixed with $2 \mu \mathrm{L}(10 \mathrm{mM})$ azido-TEG-cholesterol. Then, the reaction mixture was treated with $3 \mu \mathrm{l}$ click solution containing $1 \mu \mathrm{L}$ of $\mathrm{CuBr}$ solution $(0.01 \mathrm{~g}$ of $\mathrm{CuBr}$ in $700 \mu \mathrm{L}$ of $\mathrm{DMSO} / \mathrm{t}-\mathrm{BuOH}$ in 3:1) and $2 \mu \mathrm{L}$ Tris[(1-benzyl-1H-1,2,3-triazol-4-yl)methyl]amine (TBTA) ligand solution. $\mathrm{N}_{2}$ gas was purged to the solution and shaken for $14 \mathrm{hrs}$ in dark at room temperature. Ethanol precipitation was performed to remove unreacted reactants from the reaction mixture, and the precipitant was dissolved in $15 \mu 1$ water. The click product was analyzed and purified with the 15\% denature PAGE gel (Figures S9 and S10) and the structure was confirmed by ESI-HRMS (Figure S11).

\section{Synthesis of DNA constructs for single-molecule experiments.}

First, each of the two short single-stranded DNA fragments were conjugated with a cholesterol at the $5^{\prime}$ or $3^{\prime}$ ends by copper(II) mediated cycloaddition reaction (see the flowchart in Figure S1). Then, they were annealed with a long ssDNA containing polythymine $\left(\mathrm{T}_{40}\right)$. The annealed construct was phosphorylated to introduce the phosphate group at the 5 ' end and ligated to the 2028 bp (biotin-labeled) dsDNA handle. The ligated DNA was purified by using agarose gel which was subsequently ligated to the $2391 \mathrm{bp}$ (digoxigenin-labeled) dsDNA handle to get the final DNA construct.

To synthesize the 2028 bp DNA handle, pBR322 plasmid was taken as a template and PCR was performed by using two primers, 5'-biotin- TEG-GCA TTA GGA AGC AGC CCA GTA GTA GG 3' and 5' AAA ATC TAG AGG CTA CAC TAG AAG GAC AGT ATT TG 3' as primers. The purified PCR product was digested by using XbaI enzyme to create a cohesive end compatible with the polyT containing fragment. Similarly, to prepare the $2391 \mathrm{bp}$ handle, the $\lambda$-DNA template was used in a PCR with two primers, 5' AAA AAA AAG AGC TCC TGA CGC TGG CAT TCG CAT CAA AG 3' and 5' AAA AAA AAG GTC TCG CCT GGT TGC GAG GCT TTG TGC TTC TC 
3'. Then, SacI digestion was carried out to digest the purified PCR product, which was followed by the labeling with digoxigenin-dUTP by using terminal transferase at $3^{\prime}$ end SacI digested overhang for $8 \mathrm{hrs}$ at $37^{\circ} \mathrm{C}$. The digoxigenin-labeled product was digested by using BsaI-HFv2 enzyme, and purified, which generated an overhang that is compatible with the polyT containing fragment.

\section{Single-molecule force ramping experiments.}

Single-molecule force ramping experiments were carried out with a home-built dual-beam laser tweezers instrument. A buffer $\left(10 \mathrm{mM}\right.$ Tris and $100 \mathrm{mM} \mathrm{KCl}, \mathrm{pH} 7.4$ at $\left.23{ }^{\circ} \mathrm{C}\right)$ was used to perform all the experiments. Firstly, the final DNA construct prepared above was incubated with polystyrene bead (1.87 $\mu \mathrm{m}$ diameter) coated with streptavidin. Then, two laser traps were separately employed to capture the DNA immobilized bead and the digoxigenin antibody-coated bead (diameter $2.1 \mu \mathrm{m}$ ). By bringing two beads close to each other, the DNA construct was tethered between the two beads via affinity linkages of streptavidin/biotin and antibodydigoxigenin/digoxigenin, respectively. One of the laser traps was movable, while the other was fixed by controlling the laser beam's direction. On moving the two beads away from each other, the tethered DNA construct was stretched. During the movement, the tension was created on the cholesterol dimers, leading to the dissociation of the dimers and a sudden break was observed in the force-extension (F-X) curves. The F-X curves were recorded through LabView program (National Instruments, Austin, TX) at $1 \mathrm{kHz}$ with a loading rate of $5.5 \mathrm{pN} / \mathrm{s}$ (in the $10-30 \mathrm{pN}$ range). The force was measured based on the displacement of the bead from the center of the trap (measured by position sensitive photodetectors) and the spring constant of each trap (calibrated by the thermal motion of the bead in the trap). The presence of single molecules was confirmed by looking at the $65 \mathrm{pN}$ plateau in the F-X curve due to the phase transition of duplex DNA to a DNA form with unknown structures. ${ }^{\text {S10 }}$

The Savitzky-Golay function was used to filter the collected data (F-X curves) with a time constant of $10 \mathrm{~ms}$ in the Matlab program (The MathWorks, Natick, MA), and the mechanical stability (IMMF) of the cholesterol-cholesterol interaction was determined from the observed dissociated events in the F-X curves. 


\section{Change-in-contour-length $(\Delta L)$}

The expected $\Delta L$ during the dissociation of cholesterol dimers was calculated by the equation $(\mathrm{S} 1)$,

$$
\Delta L=L-x
$$

where $L$ is the total contour length of the $\mathrm{T}_{40}$ bridge which can be determined as, $L=L_{\mathrm{nt}} \times 40 \mathrm{nt}=$

$\sim 18 \mathrm{~nm}$, where $L_{\mathrm{nt}}$ is the contour length of a single nucleotide, $0.40-0.45 \mathrm{~nm} / \mathrm{nt},{ }^{511-13}$ and $x$ is the end-to-end distance, which is given by the sum of the length of the $5^{\prime}$ and $3^{\prime}$ ends linker ( $\left.\sim 9 \mathrm{~nm}\right)$, and the intermolecular distance between cholesterols $(\sim 1 \mathrm{~nm}) .{ }^{\mathrm{S} 14}$ This results in a total $x$ length of $\sim 10 \mathrm{~nm}$.

Therefore, the expected change-in-contour-length for a cholesterol-cholesterol interaction is $\sim(18-10)=8 \mathrm{~nm}$ which falls within the range of observations (see the rightmost histograms of Figures 2A, B and C).

\section{Data analysis}

The change in end-to-end $(\Delta x)$ is the extension difference between the stretching and the relaxing traces at a particular force $(F)$. Then, the change-in-contour-length $(\Delta L)$ was calculated from the resulting $\Delta x$ value at this force by using wormlike-chain (WLC) model (Equation S2), s15-16 as follows,

$$
\Delta x / \Delta L=1-1 / 2\left(k_{\mathrm{B}} T / F P\right)^{1 / 2}+(F / S)
$$

where $\Delta x$ is the change in end-to-end distance (or extension) between the two optically trapped beads, $\Delta L$ is the change-in-contour-length, $k_{\mathrm{B}}$ is the Boltzmann constant, $T$ is absolute temperature, $P$ is the persistent length of dsDNA $(50.8 \mathrm{~nm})$, and $S$ is the stretching modulus $(1243 \mathrm{pN}) .{ }^{\mathrm{s} 17}$

\section{Jarzynski's Calculation of the Change in Free Energy of dissociation $\left(\Delta \mathbf{G}_{\text {dissociation }}\right)$}

The change in free energy of dissociation of the cholesterol dimer or $\mathrm{Me}-\beta \mathrm{CD} / \beta \mathrm{CD}$ cholesterol complexes were calculated by using the Jarzynski non-equilibrium equation ${ }^{\mathrm{S} 18}$ :

$$
\Delta G_{\text {dissociation }}=-k_{B} T \ln \sum_{i=1}^{N} \frac{1}{N} \exp \left(-\frac{W_{i}}{k_{B} T}\right)
$$


where $k_{\mathrm{B}}$ is the Boltzmann constant, $T$ is temperature in Kelvin scale, $N$ is the total number of data points in each experiment, $W$ is the non-equilibrium work done to dissociate the dimer/complex, which was calculated by using following equation:

$W=\sum_{i=1}^{N} F_{i} \Delta x_{i}$

where $F$ and $\Delta x$ are the dissociation force and the change in end-to-end distance due to the mechanical dissociation of the dimer or the cholesterol- $\beta C D$ complex. We measured the area under the dissociation region in the F-X curve to obtain the work done to dissociate the dimer or the cholesterol- $\beta C D$ complex. However, this work also includes the work done of stretching the unfolded ssDNA from $0 \mathrm{pN}$ to the dissociation force. Therefore, this work was corrected by using a Freely-Joined-Chain model of stretched ssDNA according to the literature. ${ }^{\mathrm{S} 10,19}$

The works required to dissociate the cholesterol dimer are shown in the work histograms in the Figure S13. 


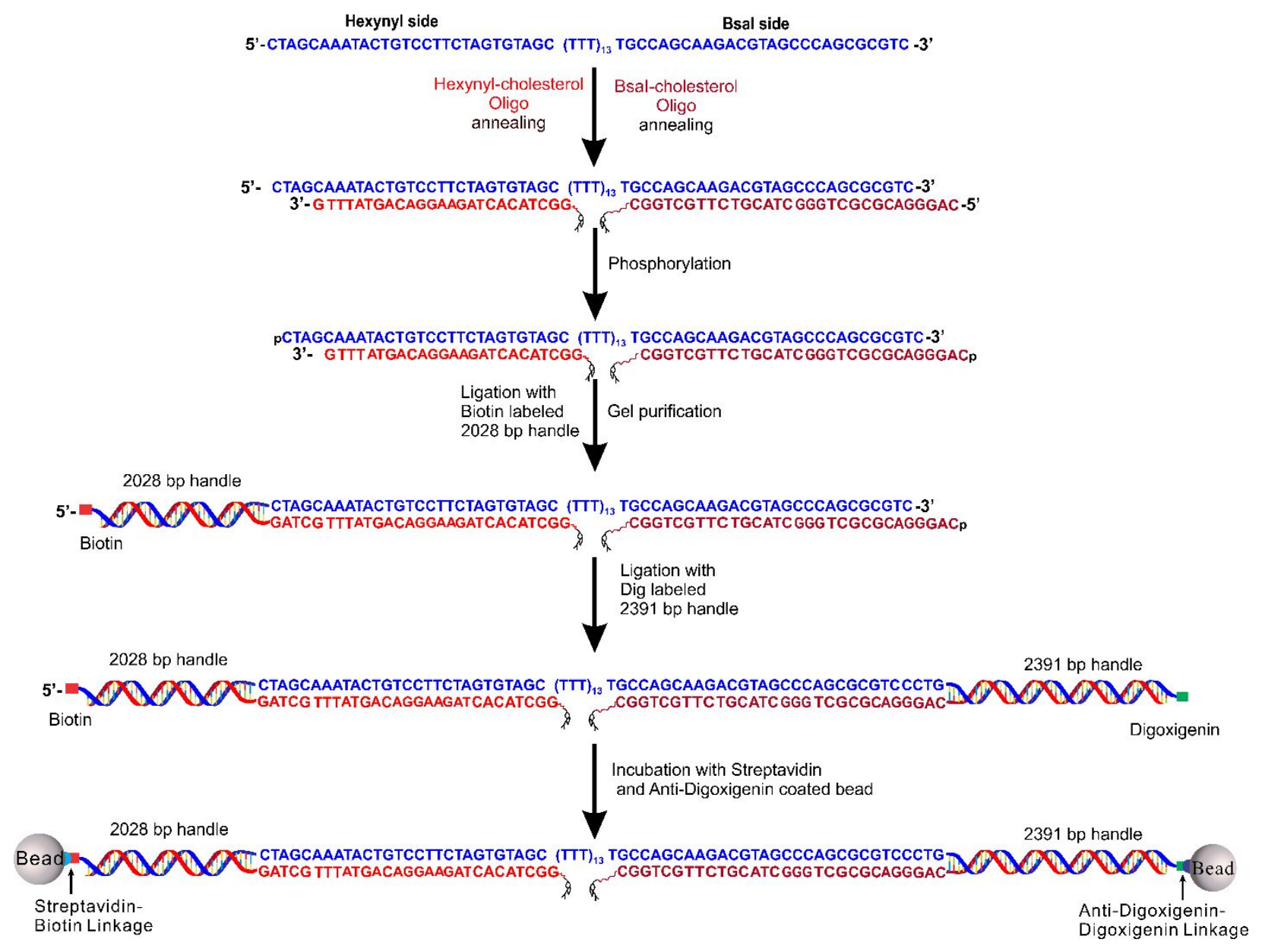

Figure S1. Flow chart for the synthesis of the cholesterol dimer construct used in the mechanochemical investigations. 


\section{Synthesis of Cholesterol Functionalized DNA}

\section{Synthesis of the 5' Cholesterol-TEG-DNA}

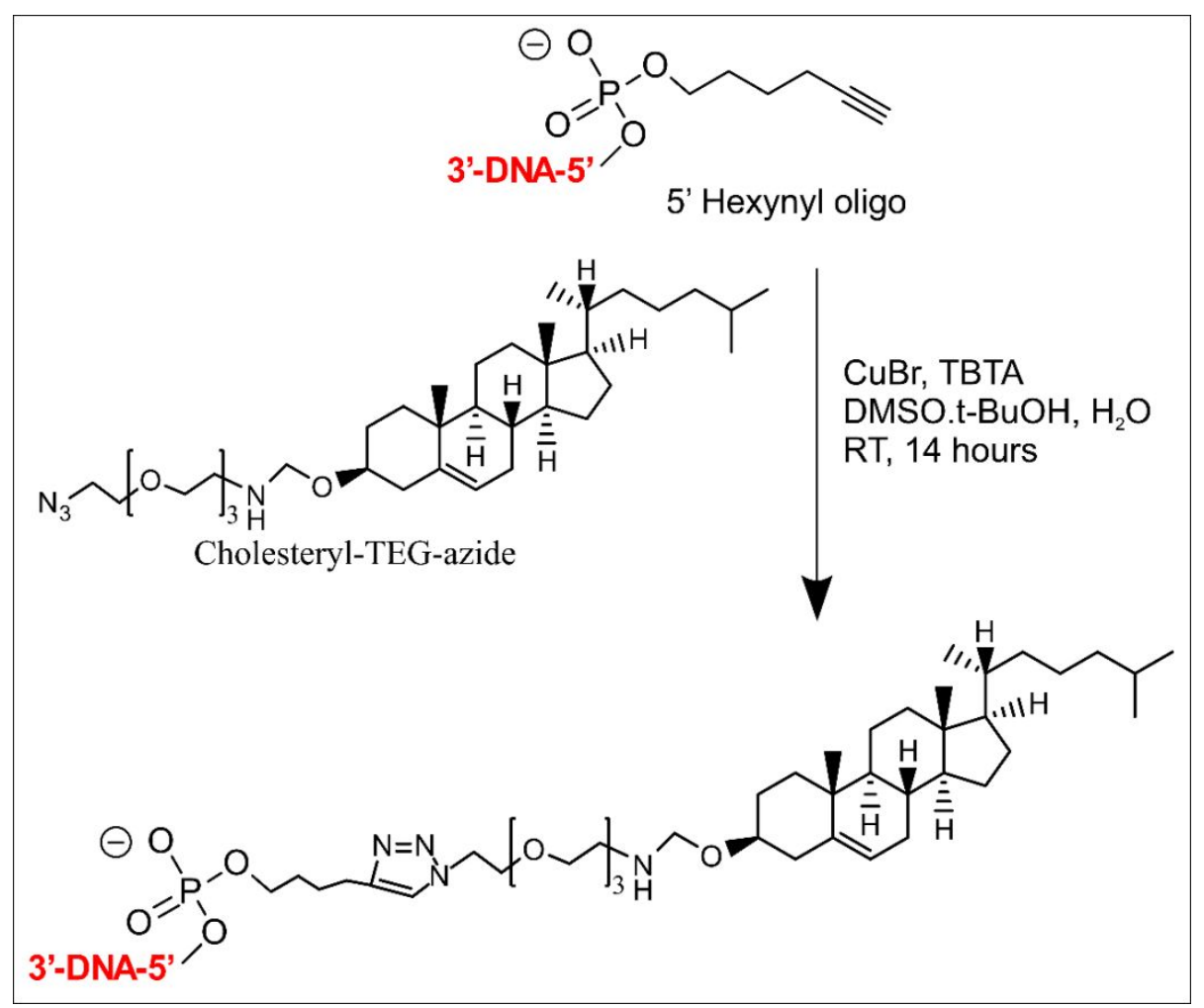

Figure S2. Synthetic scheme for the 5' Cholesterol-TEG-DNA. 


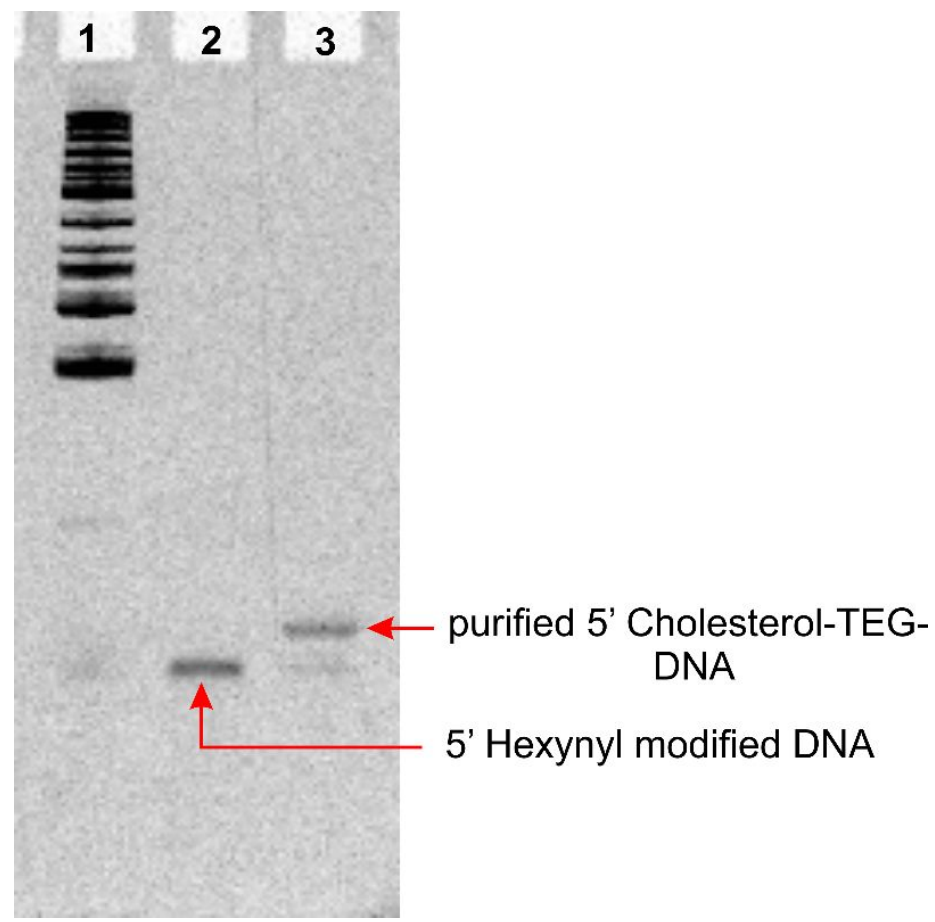

Figure S3. Purified 5' Cholesterol-TEG-DNA revealed by 15\% denaturing PAGE gel. Lane 1: Low Molecular Weight DNA Ladder (NEB); Lane 2: 5' hexynyl modified DNA (Table S1); Lane 3: the gel-purified click product of 5' Cholesterol-TEG-DNA. 
A

5' alk DNA azo chol_ESIHRMS_neg \#61-76 RT: 0.53-0.66 AV: 16 NL: 2.84E6

T: FTMS - p ESI Full lock ms [200.00-3000.00]

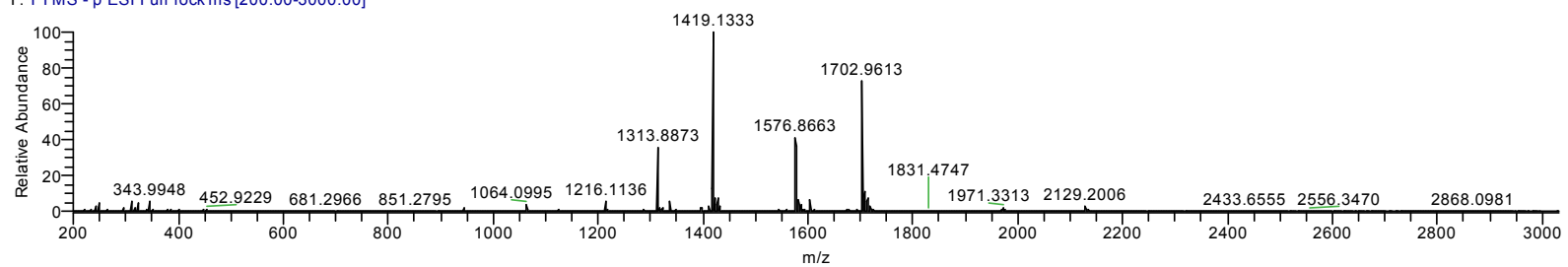

B

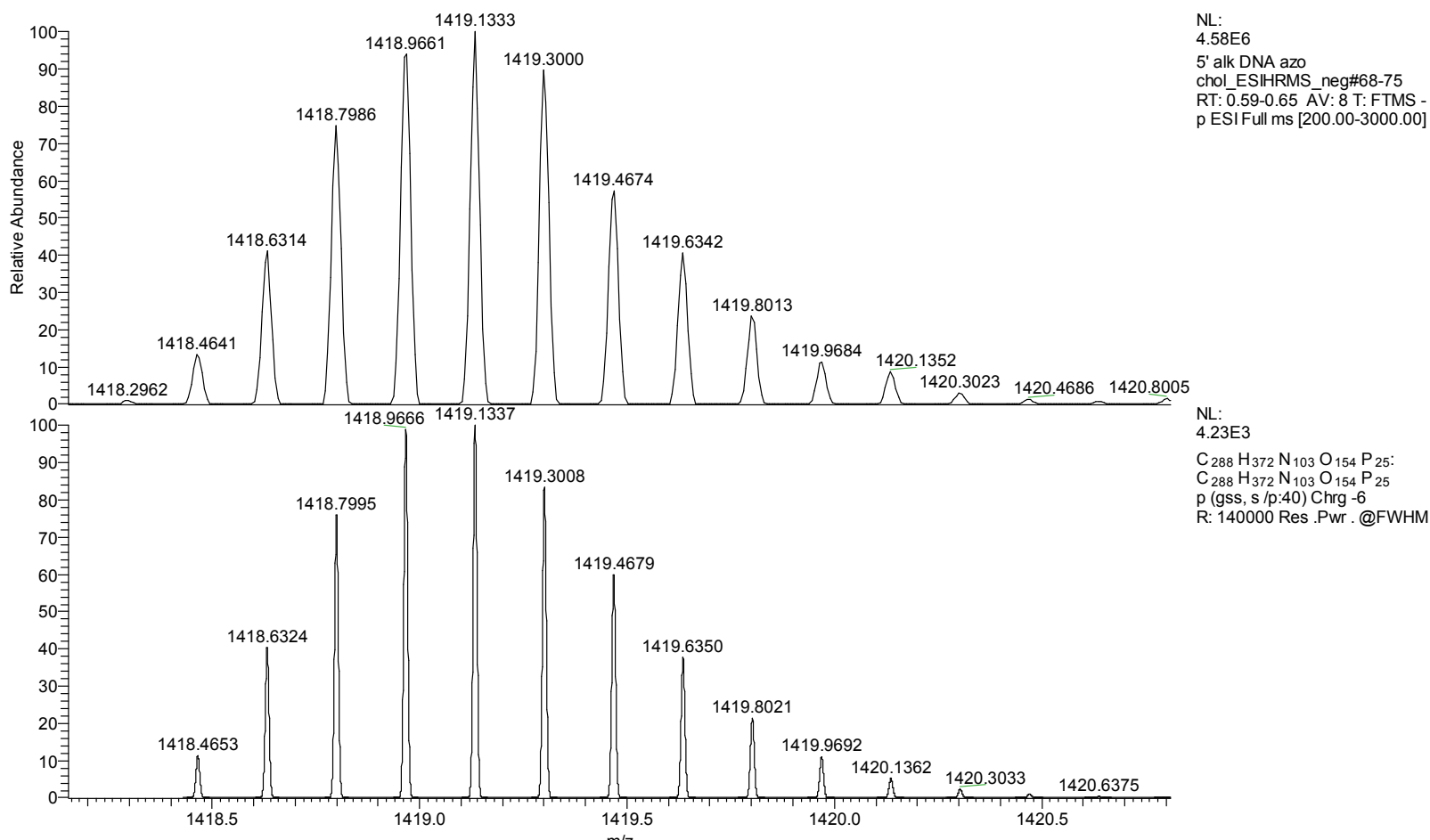

Figure S4: ESI-HRMS (negative mode) of purified 5' cholesterol-TEG-DNA taken from m/z ratio of 200-3000. A) Overview of mass spectrum of the sample from $\mathrm{m} / \mathrm{z}$ ratio of 200 to 3000 showing signals for $[M-6 H]^{6-}$ at $1419.1333 \&[M-5 H]^{5-}$ at 1702.9613. B) Zoom in view of [M$6 \mathrm{H}]^{6-}$ state signal (top) and simulated view of $[\mathrm{M}-6 \mathrm{H}]^{6-}$ state of signal (bottom), where Mimplies $\mathrm{C}_{288} \mathrm{H}_{366} \mathrm{~N}_{103} \mathrm{O}_{154} \mathrm{P}_{25}$. The observed intensed signal of [M-6H] $]^{6-}$ overlaps well with the simulated signal of the same charged state with negligible difference of $0.0024 \mathrm{Da}$. 


\section{Synthesis of the 5' Cholesterol-DNA}

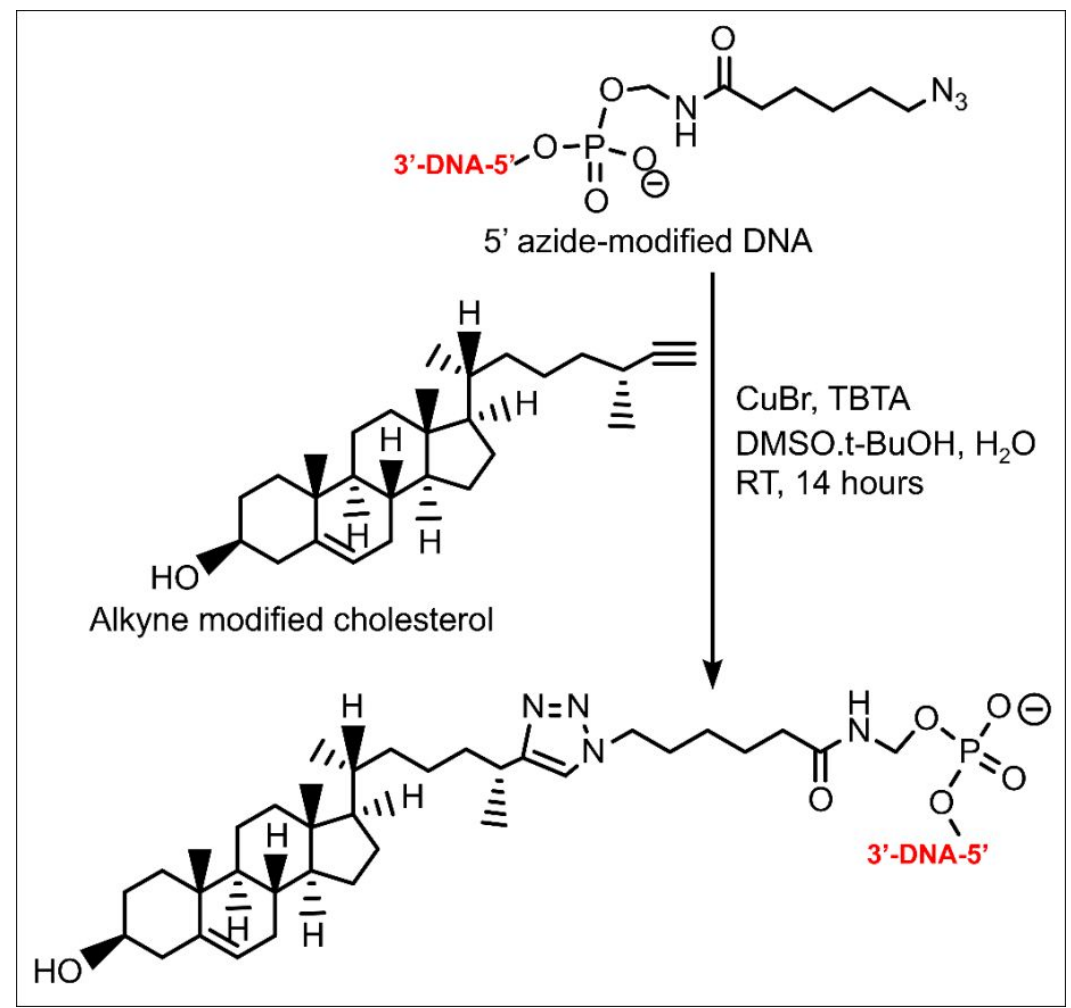

Figure S5. Synthetic scheme for the 5' Cholesterol-DNA. 


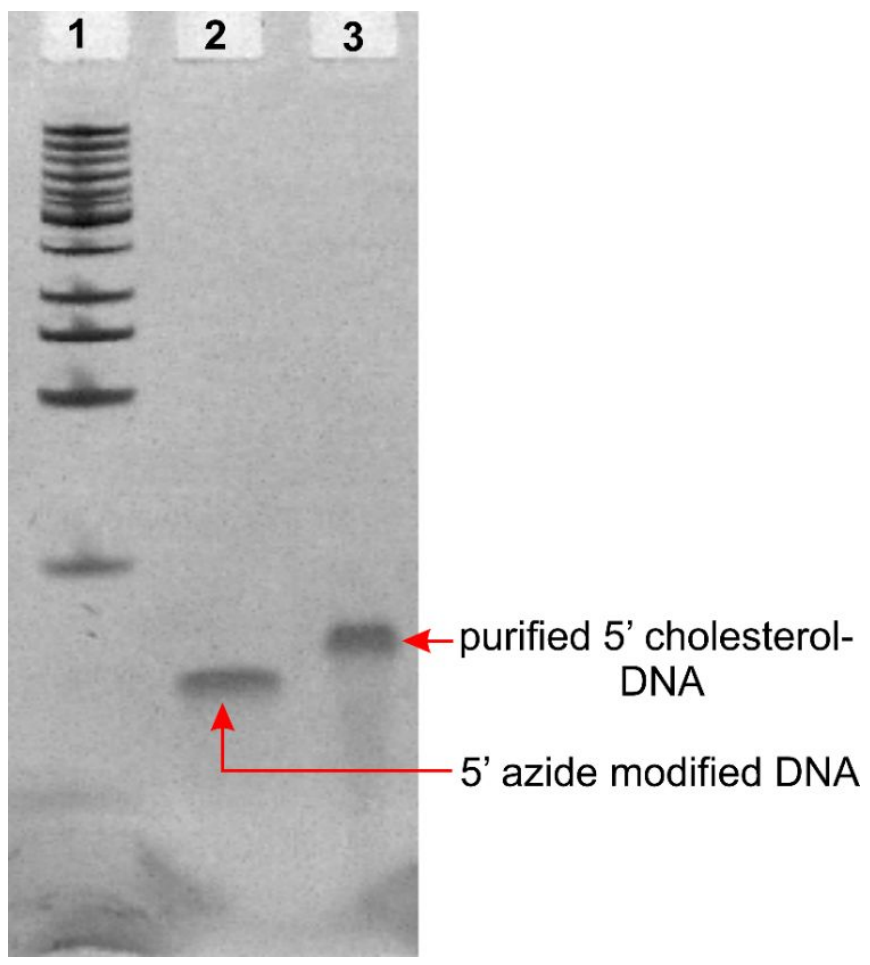

Figure S6. Purified 5' Cholesterol-DNA construct revealed by 15\% denaturing PAGE gel. Lane 1: Low Molecular Weight DNA Ladder (NEB); Lane 2: 5' azide modified DNA (Table S1); Lane 3: gel-purified click product of 5' Cholesterol-DNA. 
Synthesis of the 3' Cholesterol-propyl DNA

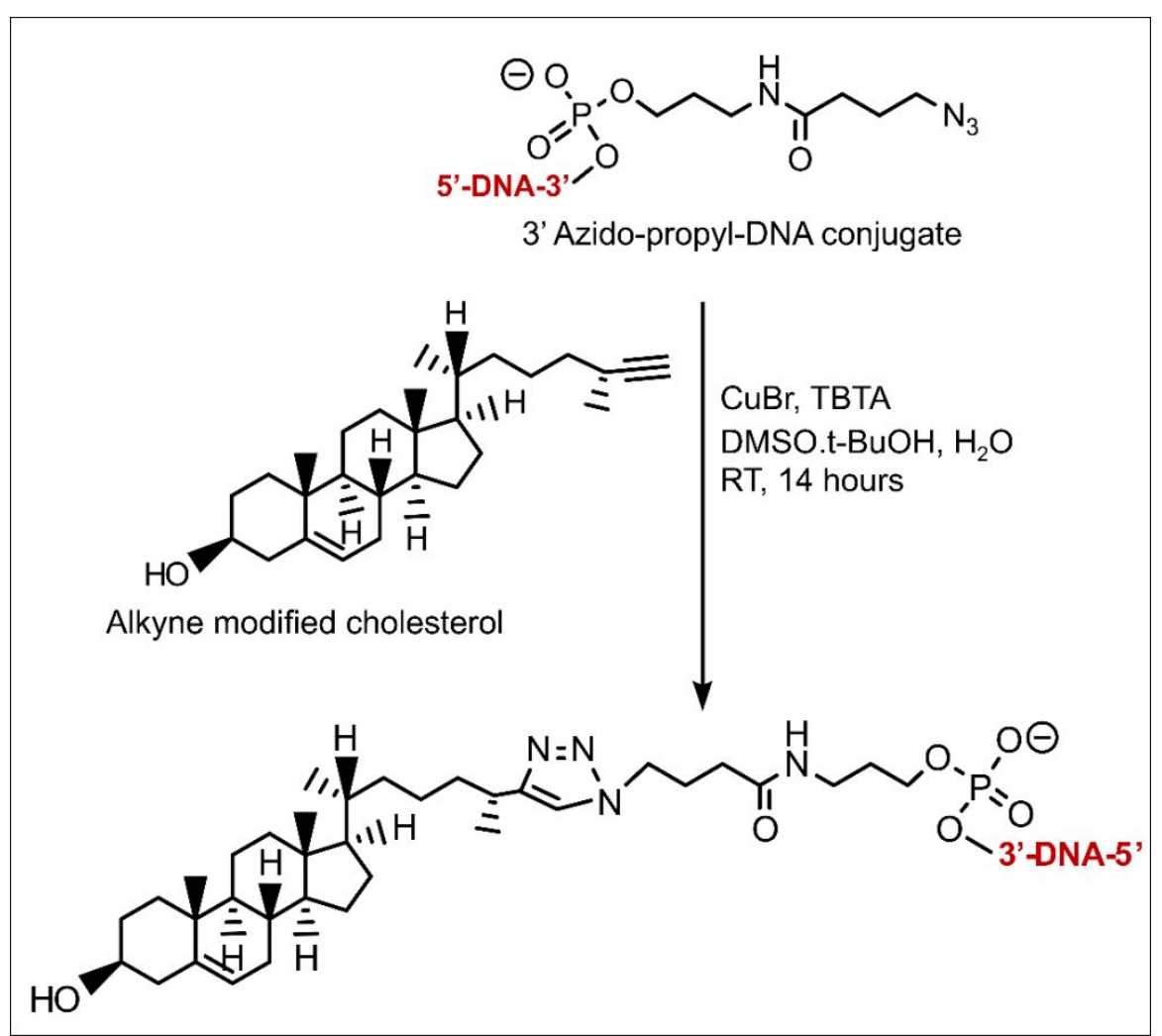

Figure S7. Synthetic scheme for the 3' Cholesterol-propyl DNA. 


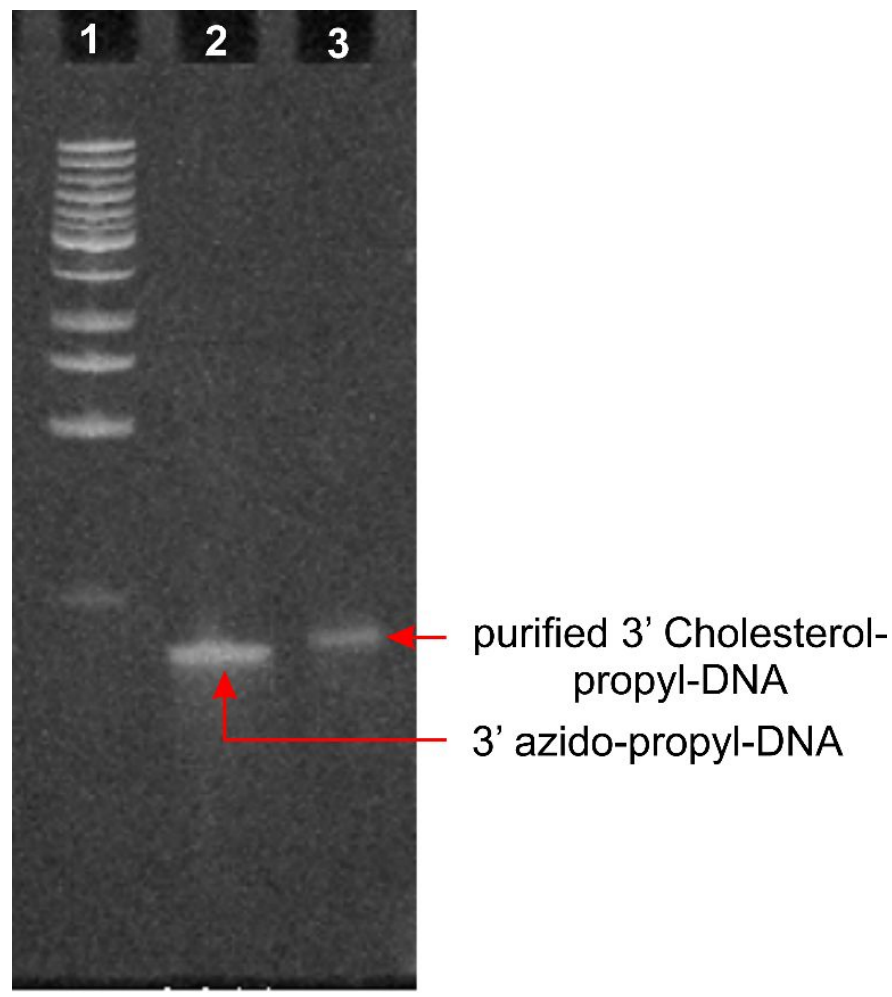

Figure S8. Purified 3' Cholesterol-propyl DNA construct revealed by 12\% denaturing PAGE gel. Lane 1: Low Molecular Weight DNA Ladder (NEB); Lane 2: 3' azido-propyl-DNA (Table S1); Lane 3: gel-purified click product of 3' Cholesterol-propyl-DNA. 


\section{Synthesis of the 3' Cholesterol-TEG-DNA}

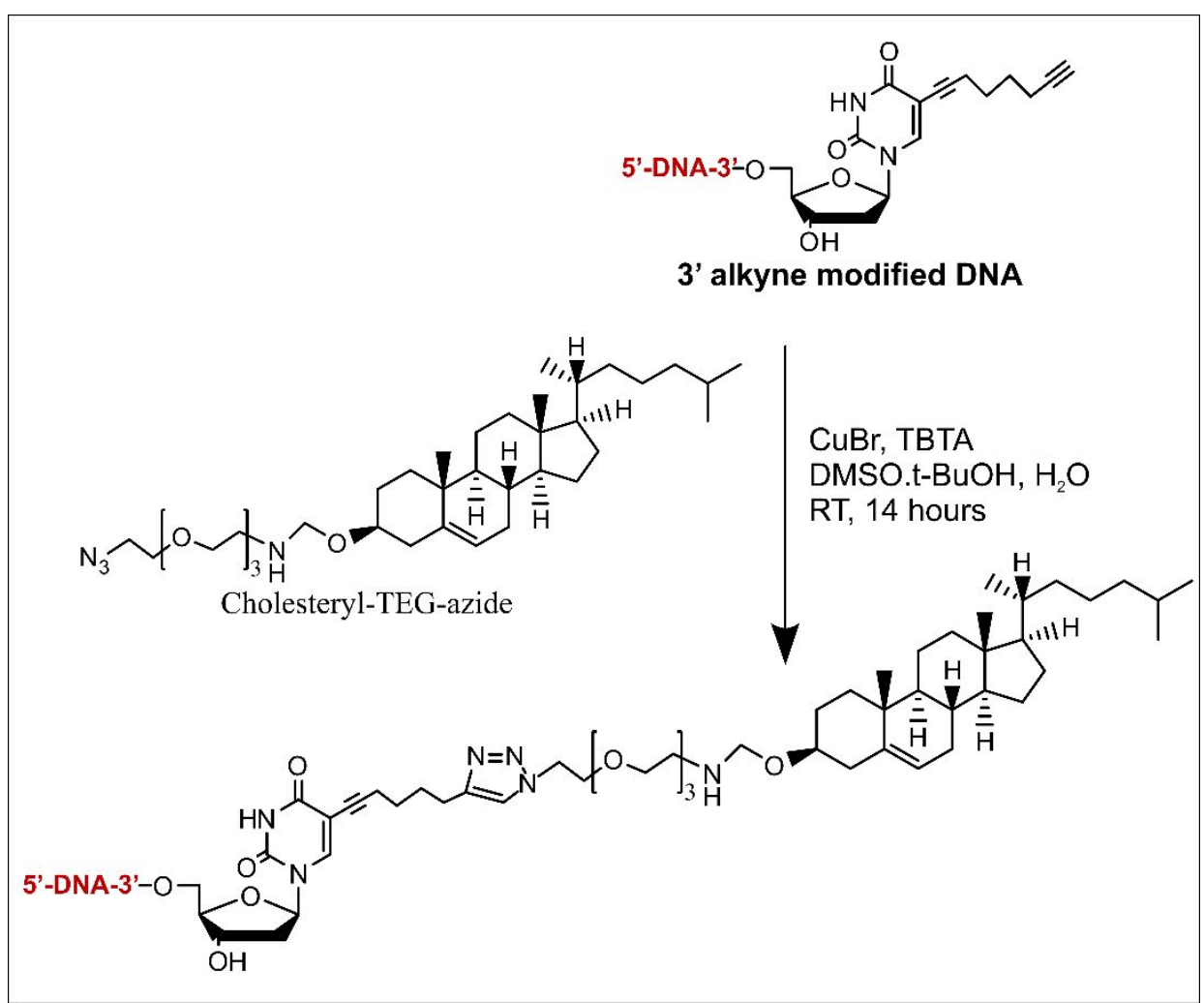

Figure S9. Synthetic scheme for the 3' Cholesterol-TEG-DNA. 


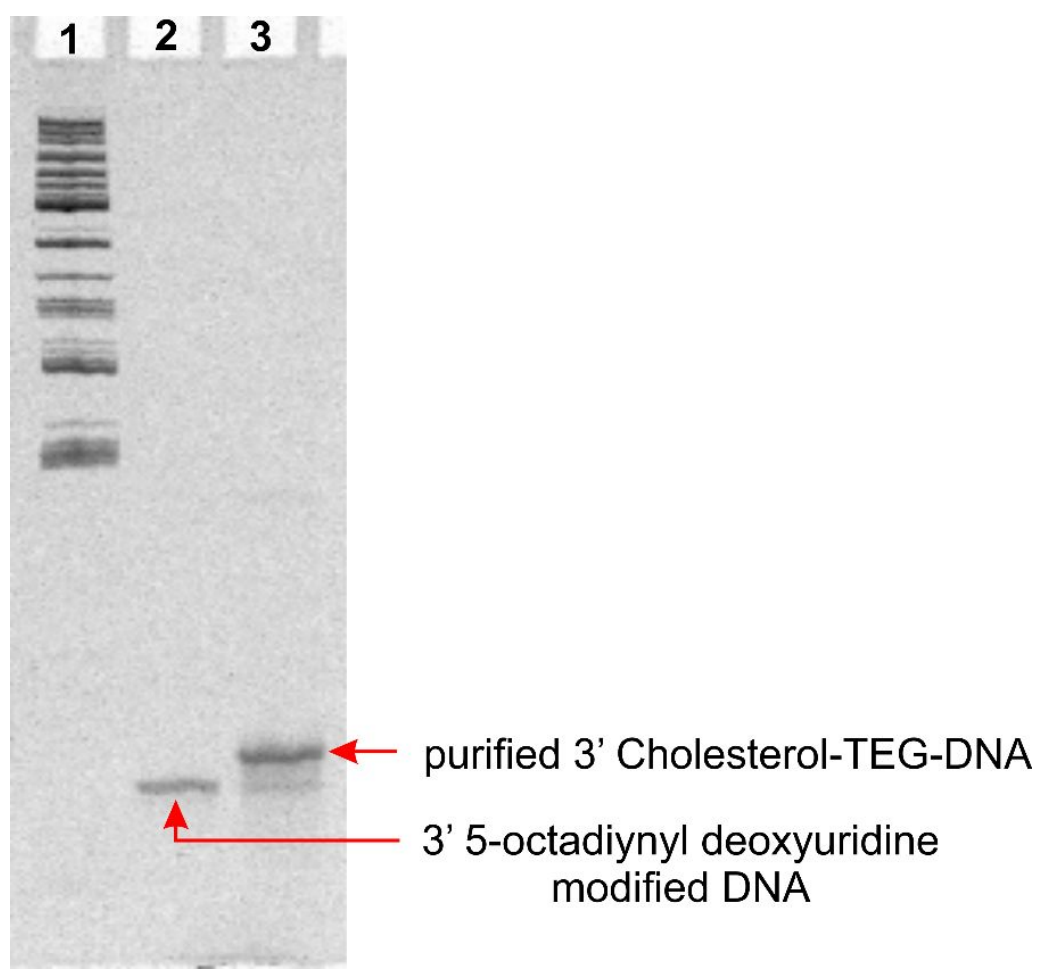

Figure S10. Purified 3' Cholesterol-TEG-DNA construct revealed by 15\% denaturing PAGE gel. Lane 1: Low Molecular Weight DNA Ladder (NEB); Lane 2: 3' 5-octadiynyl deoxyuridine modified DNA (Table S1); Lane 3: gel-purified click product of 3' Cholesterol-TEG-DNA. 
A

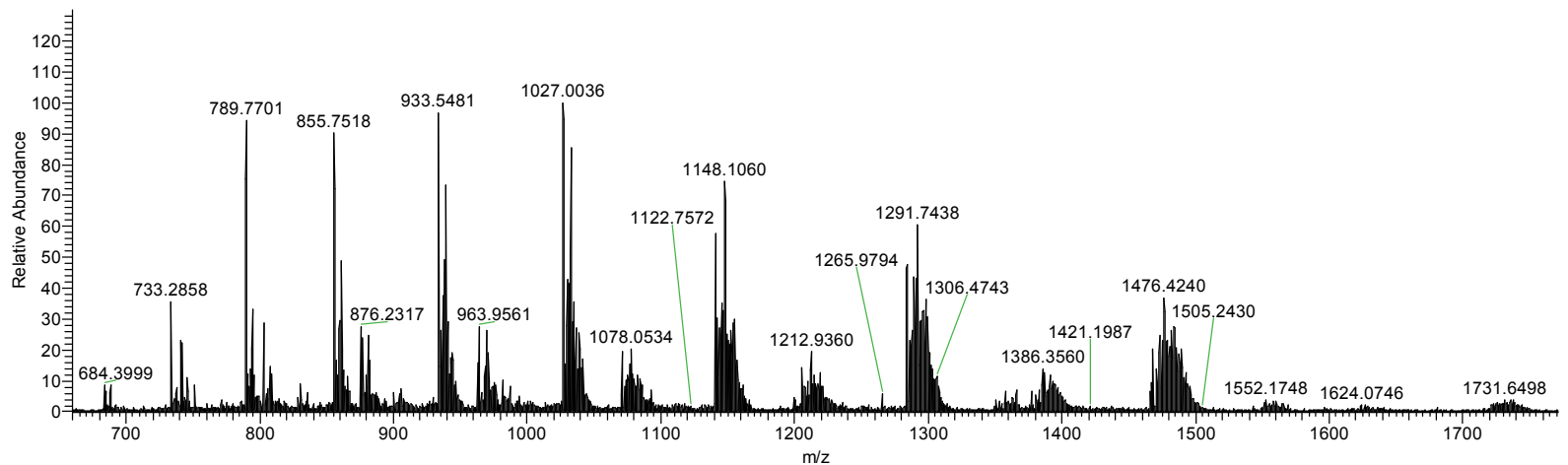

B

Molar mass of $3^{\prime}$ cholesterol-TEG-

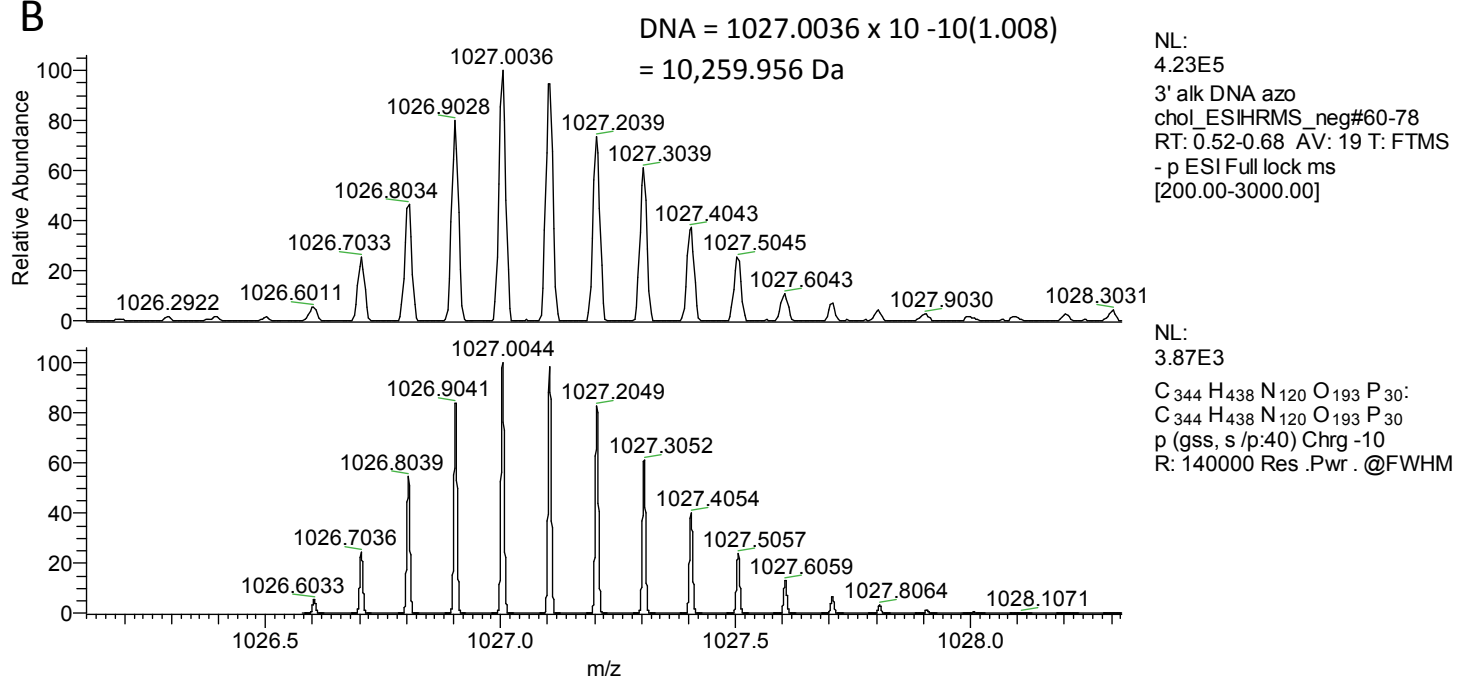

Figure S11: ESI-HRMS (negative mode) of purified 3' cholesterol -TEG-DNA taken from 660$1760 \mathrm{~m} / \mathrm{z}$. A) Overview of mass spectrum of the sample from 660 to $1760 \mathrm{~m} / \mathrm{z}$ showing the signals for $[M-x H]^{x-}$ from $x=7$ to 14 . B) Zoom in view of $[M-10 H]^{10-}$ state signal (top) and simulated view of $[\mathrm{M}-10 \mathrm{H}]^{10-}$ state of signal (bottom), where M implies $\mathrm{C}_{344} \mathrm{H}_{428} \mathrm{~N}_{120} \mathrm{O}_{193} \mathrm{P}_{30}$. The observed intensed signal of $[\mathrm{M}-10 \mathrm{H}]^{10-}$ overlaps well with the simulated signal of the same charged state with negligible difference of $0.008 \mathrm{Da}$. 


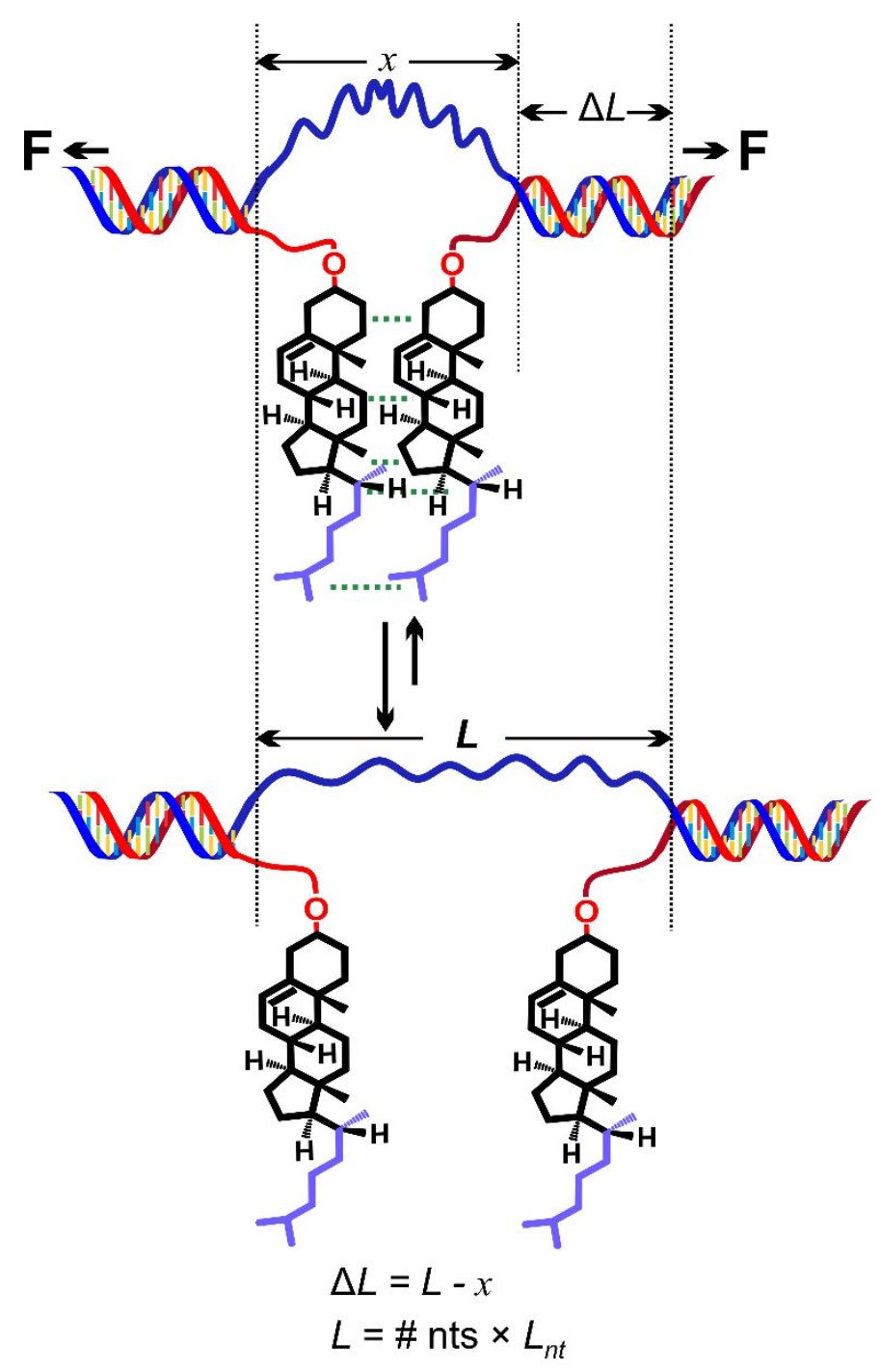

Figure S12. Relationship between the total contour length $(L)$, the change in contour length $(\Delta L)$ during the dissociation of cholesterol dimer, and the end-to-end distance (x). 


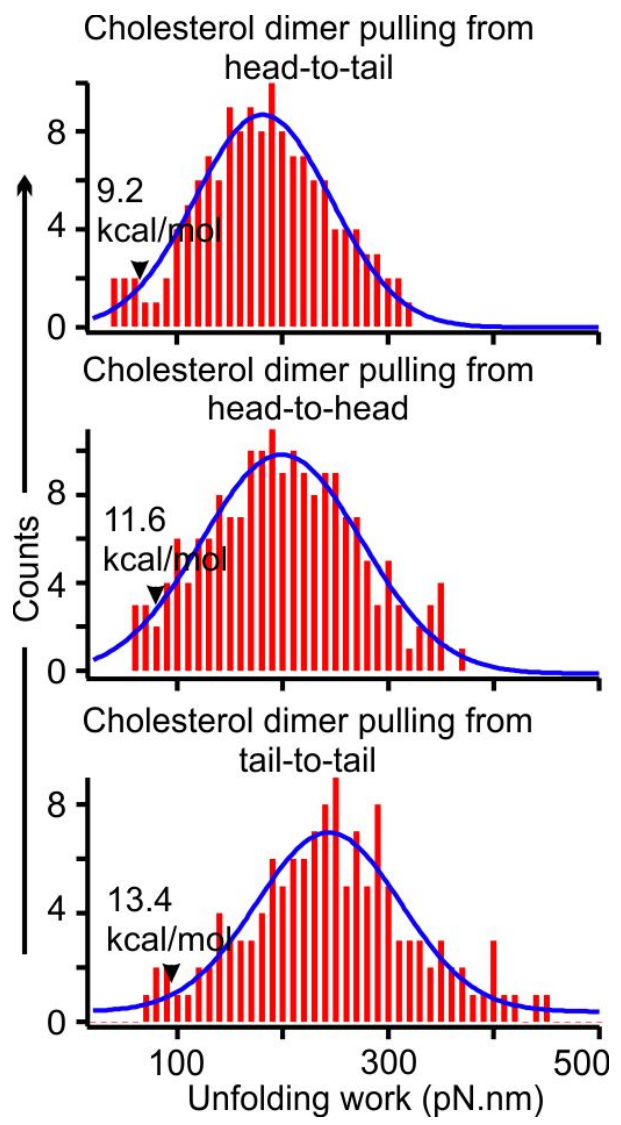

Figure S13. Dissociation work histograms of the cholesterol dimer pulling from the head-to-tail (top), head-to-head (middle), and tail-to-tail (bottom). Arrowheads depict the works equivalent to

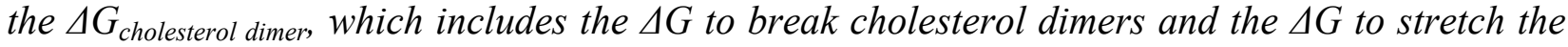
T40 loop. Solid curves represent Gaussian fittings. 


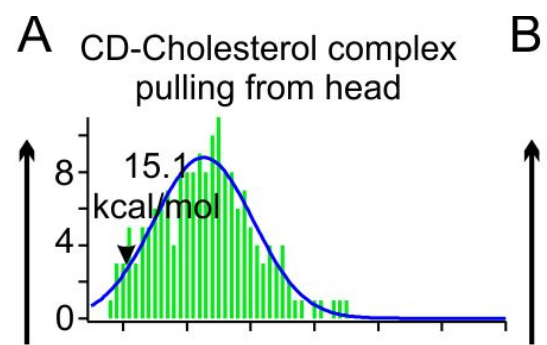

B Me-CD-Cholesterol complex pulling from head
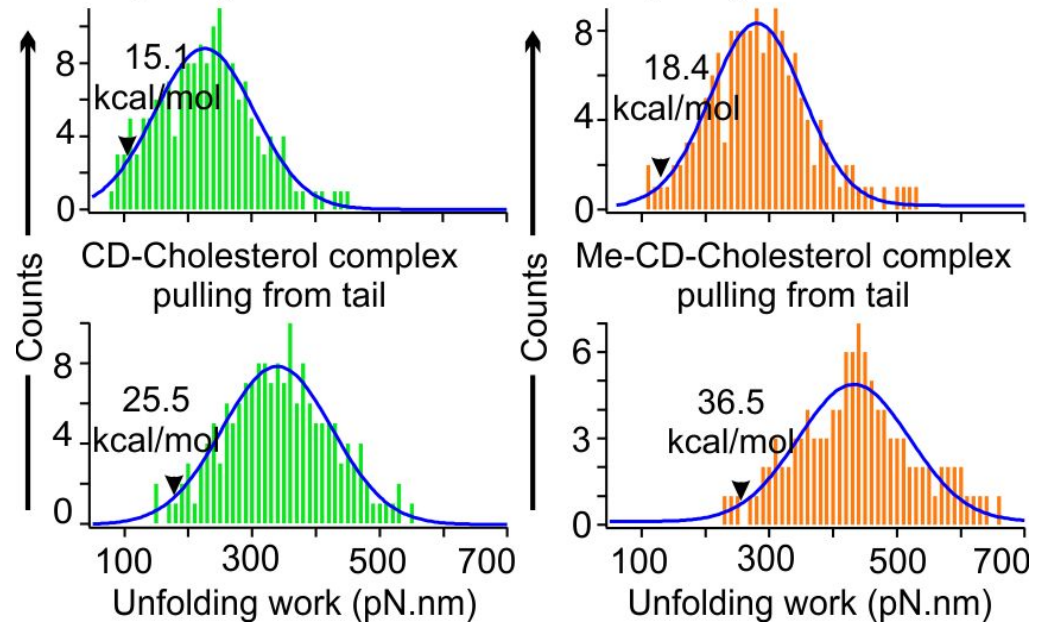

Figure S14. A) Dissociation work histograms of the CD-cholesterol complexes pulling from the head (top) and tail (bottom). B) Dissociation work histograms of the Me-CD-cholesterol complexes pulling from head (top) and tail (bottom). Arrowheads depict the works equivalent to the $\Delta G_{C D / M e-}$ CD-cholesterol complex, which includes the $\Delta G$ to break the CD/Me-CD-cholesterol complex and the $\Delta G$ to stretch the T40 loop. Solid curves represent Gaussian fittings. 
Cholesterol dimer pulling from head-to-tail

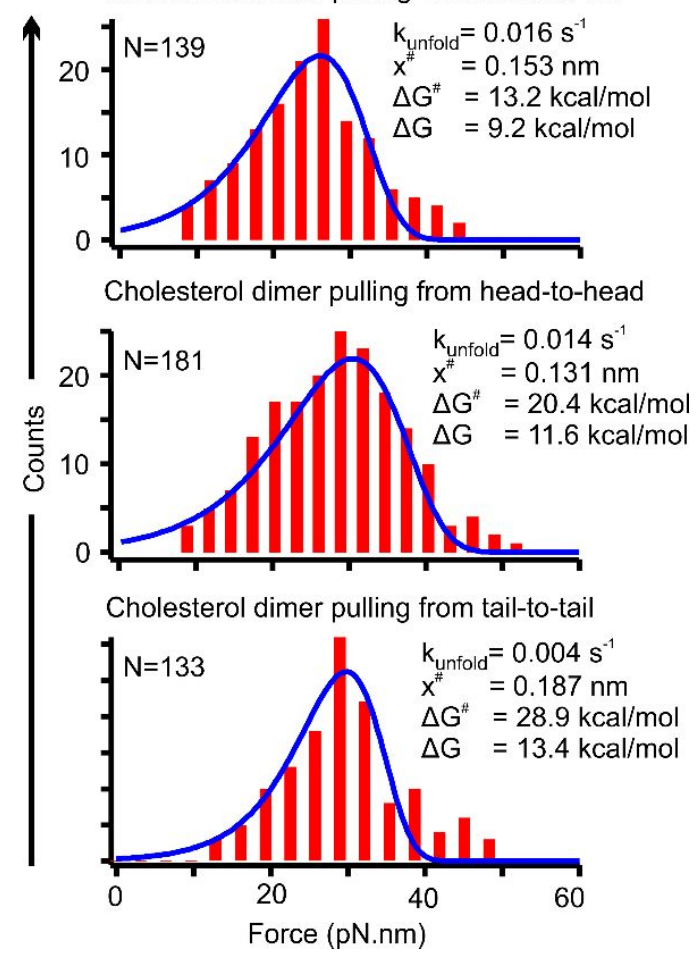

Figure S15. Dudko fittings of the unfolding force histograms for the cholesterol dimer complexes pulled from the head-to-tail (top), head-to-head (middle), and tail-to-tail (bottom) orientations. 

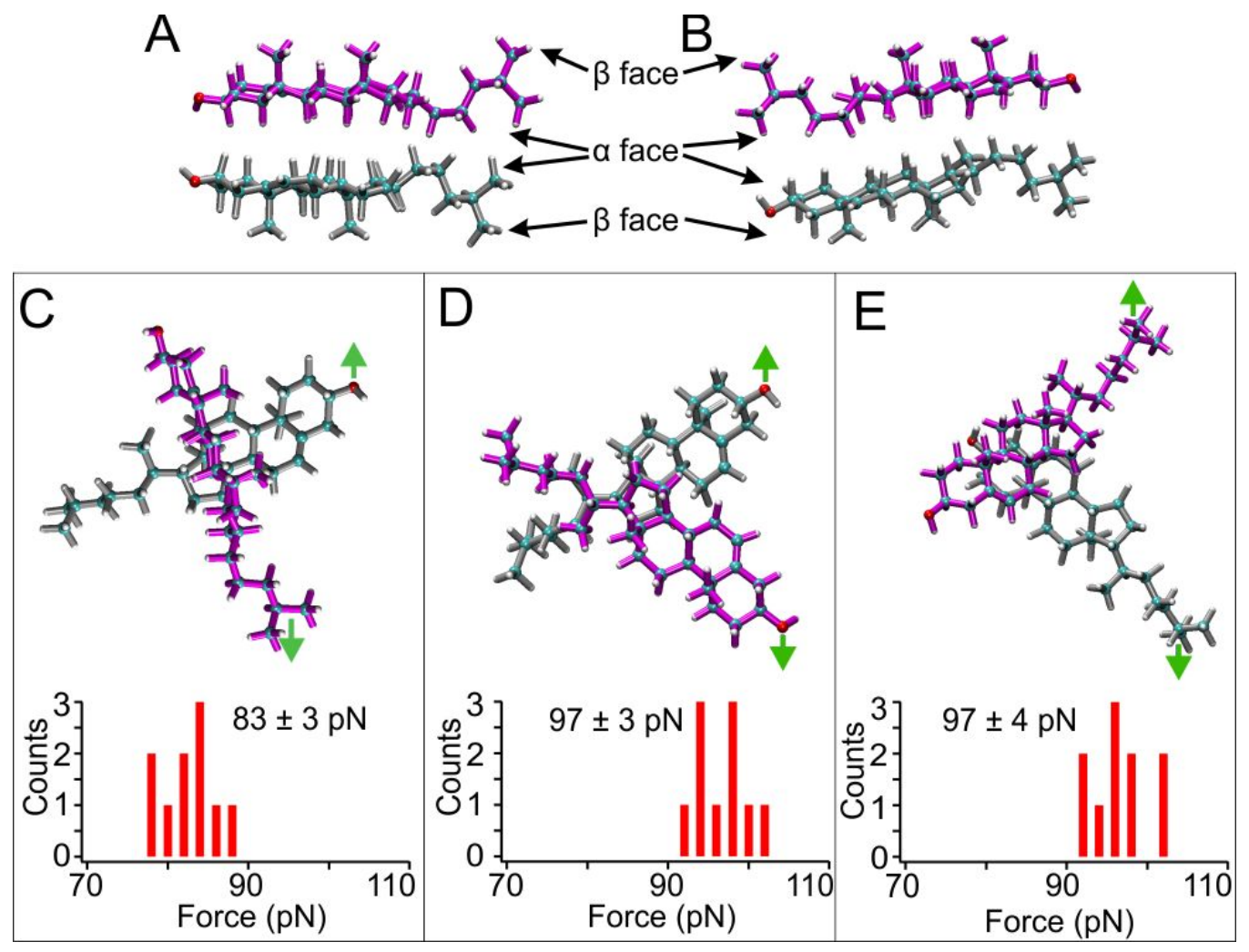

Figure S16. Molecular dynamic simulations of cholesterol pulling along the plane of the cholesterol dimer at different orientations. Head-to-head/Tail-to-tail orientation (A) and Head-totail orientation (B) of cholesterol dimers. $\boldsymbol{C}$ ) Molecular view of cholesterol molecules pulling from the Head-to-tail direction (Top) and the corresponding dissociation force histogram (Bottom). D) Molecular view of cholesterol molecules pulling from the Head-to-head direction (Top) and the corresponding dissociation force histogram (Bottom). E) Molecular view of cholesterol molecules pulling from the Tail-to-tail direction (Top) and the corresponding dissociation force histogram (Bottom). Arrow heads show the pulling directions. 


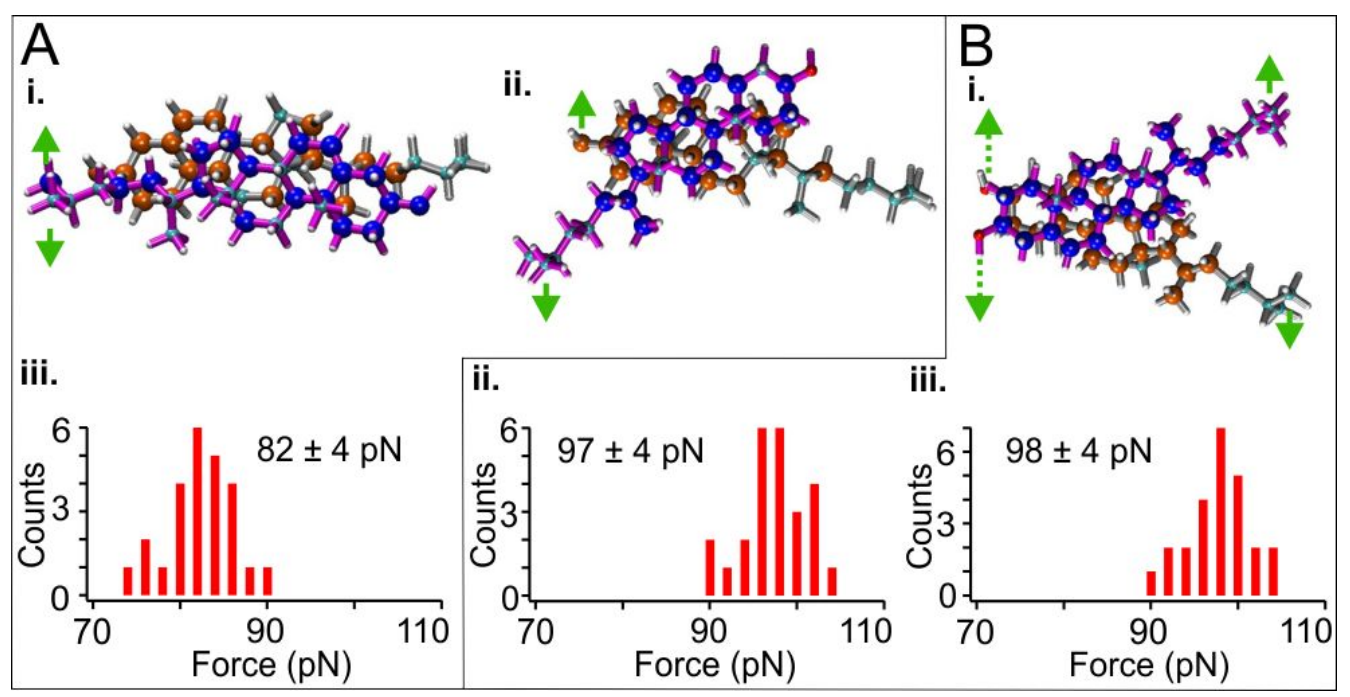

Figure S17. Molecular dynamic simulations of cholesterol pulling out of the plane of the cholesterol dimer at different orientations. A) Molecular top view of cholesterol molecules pulling from the Head-to-tail direction at different configurations $(i \&$ ii) and the corresponding force histogram (iii). B) i) Molecular top view of cholesterol molecules pulling from the Head-to-head (dotted arrow)/Tail-to-tail directions (solid arrow) and the corresponding dissociation force histograms (ii \& iii for Head-to-head and Tail-to-tail pulling, respectively). 
Table S1. Sequences of the DNA oligos used in this work.

\begin{tabular}{|l|l|}
\hline DNA Conjugate & DNA Sequence Used (5'-3') \\
\hline 5'Cholesterol-TEG-DNA & GGC TAC ACT AGA AGG ACA GTA TTT G \\
\hline 5' Cholesterol-DNA & GGC TAC ACT AGA AGG ACA GTA TTT G \\
\hline 3'Cholesterol-propyl DNA & CAG GGA CGC GCT GGG CTA CGT CTT GCT GGC \\
\hline 3'Cholesterol-TEG-DNA & CAG GGA CGC GCT GGG CTA CGT CTT GCT GGC \\
\hline
\end{tabular}

Table S2. Summary of change in dissociation free energy and dissociation force for different orientations of cholesterol dimers.

\begin{tabular}{|l|l|l|}
\hline $\begin{array}{l}\text { Cholesterol dimer } \\
\text { orientations }\end{array}$ & $\begin{array}{l}\text { Change in dissociation free } \\
\text { energy calculated from } \\
\text { Jarzynski equality } \\
(\mathrm{kcal} / \mathrm{mol})\end{array}$ & Dissociation Force $(\mathrm{pN})$ \\
\hline Head-to-Tail & $9.2 \pm 1.6$ & 24 \\
\hline Head-to-Head & $11.6 \pm 0.7$ & 29 \\
\hline Tail-to-Tail & $13.4 \pm 0.9$ & 31 \\
\hline
\end{tabular}




\section{Supporting References}

S1. Plimpton, S., Fast Parallel Algorithms for Short-Range Molecular Dynamics. Journal of Computational Physics 1995, 117(1), 1-19.

S2. R W Hockney, J. W. E., Computer Simulation Using Particles. 25 March 2021 ed.; Taylor and Francis group: Boca Raton, London, 1988; p 540.

S3. Allen, M. P.; Tildesley, D. J.; Press, O. U., Computer Simulation of Liquids. Clarendon Press: 1987.

S4. Kitson, D. H.; Hagler, A. T., Theoretical studies of the structure and molecular dynamics of a peptide crystal. Biochemistry 1988, 27(14), 5246-5257.

S5. Breneman, C. M.; Wiberg, K. B., Determining atom-centered monopoles from molecular electrostatic potentials. The need for high sampling density in formamide conformational analysis. Journal of Computational Chemistry 1990, 11 (3), 361-373.

S6. Berendsen, H. J. C.; Postma, J. P. M.; van Gunsteren, W. F.; Hermans, J., Interaction Models for Water in Relation to Protein Hydration. In Intermolecular Forces: Proceedings of the Fourteenth 
Jerusalem Symposium on Quantum Chemistry and Biochemistry Held in Jerusalem, Israel, April

13-16, 1981, Pullman, B., Ed. Springer Netherlands: Dordrecht, 1981; pp 331-342.

S7. Teleman, O.; Jönsson, B.; Engström, S., A molecular dynamics simulation of a water model with intramolecular degrees of freedom. Molecular Physics 1987, 60 (1), 193-203.

S8. Wang, J.; Wolf, R. M.; Caldwell, J. W.; Kollman, P. A.; Case, D. A., Development and testing of a general amber force field. Journal of Computational Chemistry 2004, 25 (9), 11571174.

S9. Huang, J.; MacKerell, A. D., Jr., CHARMM36 all-atom additive protein force field: validation based on comparison to NMR data. Journal of computational chemistry 2013, 34 (25), 2135-2145.

S10. Smith, S. B.; Cui, Y. J.; Bustamante, C., Overstretching B-DNA: The elastic response of individual double-stranded and single-stranded DNA molecules. Science 1996, 271 (5250), 795799. 
S11. Yu, Z.; Schonhoft, J. D.; Dhakal, S.; Bajracharya, R.; Hegde, R.; Basu, S.; Mao, H., ILPR G-Quadruplexes Formed in Seconds Demonstrate High Mechanical Stabilities. J. Am. Chem. Soc. 2009, $131(5), 1876-1882$.

S12. Mills, J. B.; Vacano, E.; Hagerman, P. J., Flexibility of single-stranded DNA: use of gapped duplex helices to determine the persistence lengths of poly(dT) and poly(dA). J. Mol. Biol. 1999, $285,245-257$.

S13. Tinland, B.; Pluen, A.; Sturm, J.; Weill, G., Persistence Length of Single-Stranded DNA. Macromolecules 1997, 30, 5763-5765.

S14. Andoh, Y.; Oono, K.; Okazaki, S.; Hatta, I., A molecular dynamics study of the lateral free energy profile of a pair of cholesterol molecules as a function of their distance in phospholipid bilayers. The Journal of Chemical Physics 2012, 136 (15), 155104.

S15. Baumann, C. G.; Smith, S. B.; Bloomfield, V. A.; Bustamante, C., Ionic effects on the elasticity of single DNA molecules. Proceedings of the National Academy of Sciences 1997, 94 (12), 6185-6190. 
S16. Yu, Z.; Mao, H., Non-B DNA structures show diverse conformations and complex transition kinetics comparable to RNA or proteins a perspective from mechanical unfolding and refolding experiments. Chem. Rec. 2013, 13, 102-116.

S17. Dhakal, S.; Cui, Y.; Koirala, D.; Ghimire, C.; Kushwaha, S.; Yu, Z.; Yangyuoru, P. M.; Mao, H., Structural and mechanical properties of individual human telomeric G-quadruplexes in molecularly crowded solutions. Nucleic Acids Res. 2013, 41, 3915-3923.

S18. Jarzynski, C., Nonequilibrium Equality for Free Energy Differences. Phys. Rev. Lett. 1997, $78,2690-2693$.

S19. Greenleaf, W. J.; Frieda, K. L.; Foster, D. A.; Woodside, M. T.; Block, S. M., Direct observation of hierarchical folding in single riboswitch aptamers. Science 2008, 319, 630-633. 